\title{
ÉLITES HISPANIQUES
}

TEXTES RÉUNIS PAR

Milagros NAVARRO CABALLERO \& SÉgolène DEMOUGIN

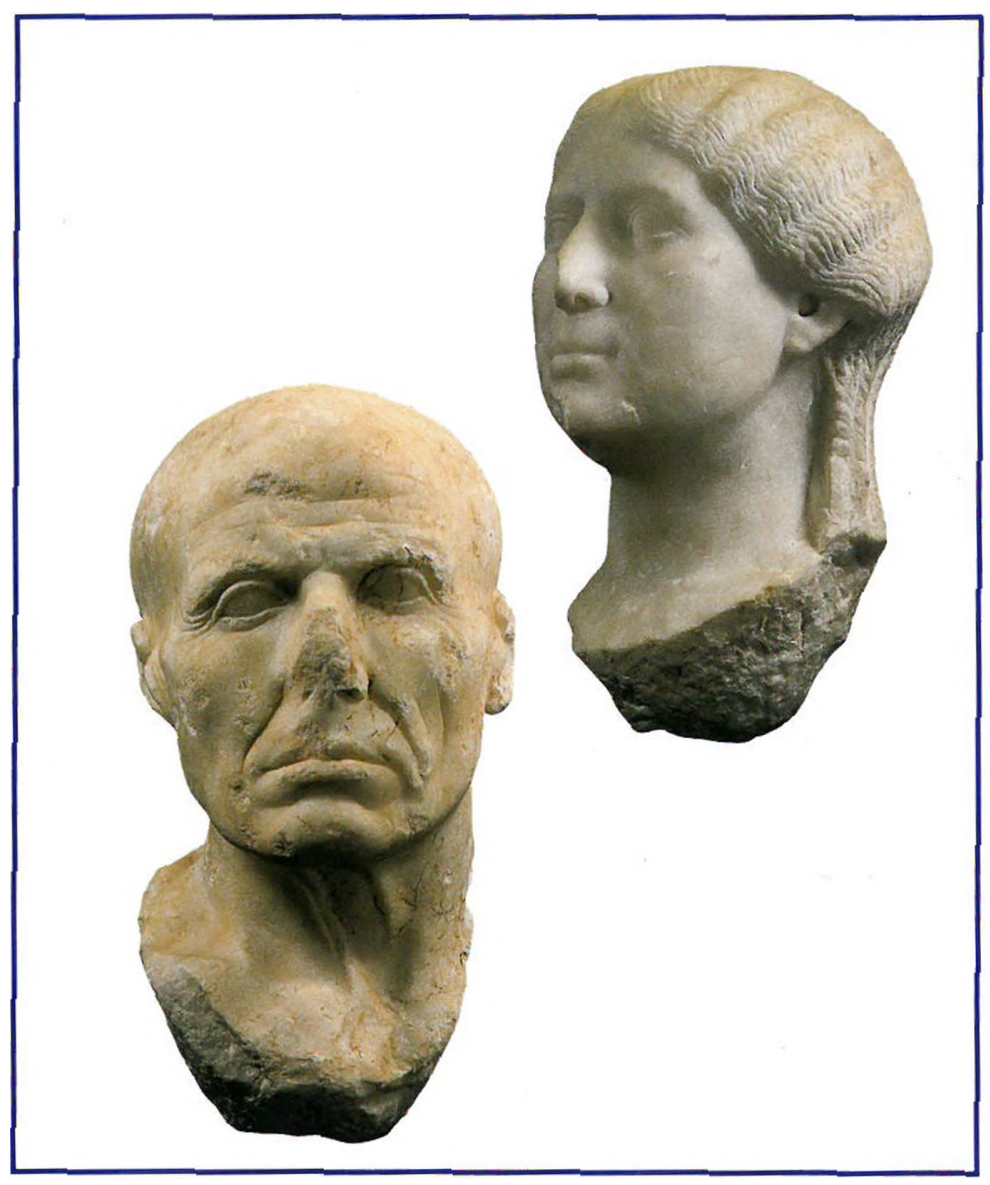




\section{ÉLITES HISPANIQUES}

Séminaire Bordeaux, décembre 1998

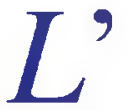

histoire des élites hispaniques dans l'Empire romain est marquée par la double forme de leur recrutement. Rome, confrontée à des structures sociales préexistantes, dominées par une élite indigc̀nc, imposa pctit à pctit son propre modèle social. L'attirance fut progressive, mais irrésistible. Les contributions réunies dans ce volume apportent un éclairage nouveau sur la définition et la constitution de ces élites. identifiées par la possession de patrimoines économiques, sociaux, culturels et symboliques, dont elles veulent assurer la pérennité.

Ainsi apparut une aristocratie proprement hispanique, assumant pleinement son rôle dans les structures sociales romaines : non seulement, ses plus brillants éléments participèrent à l'exercice du pouvoir, mais plus encore ils finirent par obtenir le trône. Cette réussite scelle le destin des élites hispaniques.

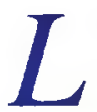

a historia de las elites hispánicas en el Imperio romano está caracterizada por un doble proceso de creación. Roma, enfrentada a las estructuras sociales preexistentes, dominadas por una aristocracia indigena, impuso de forma palatina su propio modelo social. La atracción fue progresiva pero irresistible. Los articulos reunidos en este volumen aportan una nueva visión sobre la definición y la formación de estas elites, identificadas por la posesión de patrimonios económicos, sociales, culturales y simbólicos, de los que quieren asegurar la perennidad.

Así surgió una aristocracia propiamente hispánica, asumiendo plenamente su papel en las estructuras sociales romanas : no solamente sus más brillantes elementos participaron en el ejercicio del poder, sino que terminaron alcanzando el trono. Este destino consagra el éxito de las elites hispánicas.

$T$ he history of the elites from the Spanish provinces in the Roman Empire is remarkable for the double process that was involved in their formation. Rome was faced with pre-existing social structures, dominated by an indigenous elite, but managed to impose step by step its own social model. The attraction towards this model was gradual, but in the end irresistible. The papers contained in this volume throw new light on the definition and social makeup of these elites, whose defining feature was the possession of an economic, social, cultural and symbolic inheritance, which the elites wished to preserve for all time.

In this way a truly Hispanic aristocracy developed, that played a full role in Roman society. Not only did its most illustrious members exercise power, but some even went so far as to became Roman emperors. This success at the very centre of power is a hallmark of the elites of the Iberian peninsula under Roman rule. 


\title{
AUSONIUS - PUBLICATIONS \\ Études 6
}

\section{ÉLITES HISPANIQUES}

\author{
Textes réunis par \\ Milagros NAvarRo CABALlero \\ et Ségolène DEMOUGIN
}

avec la collaboration de Françoise DES BOSCS-PLATEAUX

Diffusion De BocCARD 11 rue de Médicis F - 75006 PaRIS

- Bordeaux 2001 - 


\section{AUSONIUS}

Maison de l'Archéologie

Université Michel de Montaigne - Bordeaux III

F - 33607 Pessac Cedex

Directeur des Publications : Alain BRESSON

Secrétaire des Publications : Stéphanie VINCENT

Graphisme de Couverture : Stéphanie VINCENT

(c) AUSONIUS 2001

ISSN : $1283-2200$

ISBN : 2-910023-23-0

Imprime : Gráficas Calima, S. A.

Avda. Candina. s/n

E - 39011 Santander - Cantabria 


\section{SOMMAIRE}

Alain Tranoy, INTRODUCTION.

\section{L’originalité des élites hispaniques}

Géza ALFöLDY, Présentation

José Luis Ramírez SÁdABA, El nacimiento de las elites de Augusta Emerita

Sylvie DARDAINE, La naissance des élites hispano-romaines en Bétique

Patrick LE ROUX, La "crise" des élites hispaniques (III'-IV" siècles)

Les fondements économiques de la puissance des élites hispaniques

Jonathan EDMONdson, Présentation

Antonio Caballos Rufino, Los recursos económicos de los notables de la Bérica

Robert ÉTIENNE et Françoise MAYET, Les élites marchandes

de la péninsule Ibérique.

\section{La transmission des modèles romains}

Pierre Gros, Présentation

María luisa CANCELA RAMÍREZ de ARELLANO, Los monumentos funerarios

de las elites locales hispanas

Trinidad Nogales BasarRate, Autorrepresentación de las elites provinciales: el ejemplo de Augusta Emerita.

Armin U. STYLOW, Las estatuas honorificas como medio de autorrepresentación de las elites locales de Hispania

Enrique MELCHOR GIL, Consideraciones sobre la munificencia civica en la Bética romana

Pierre SILLIÈRES, La maison aristocratique à l'époque républicaine, principalement dans la vallée de l'Ébre 
Les élites et le pouvoir

Antonio Caballos Rufino, Présentation

Milagros NAVARRo CABALLERO, Les femmes de l'élite hispano-romaine, entre la famille et la vie publique.

Françoise DES BOSCS-PlATEAUX, Les sénateurs hispaniques

et le pouvoir d'Auguste à Trajan.

203

Sabine LEFEBVRE. Q. (Lucceius Albinus), flamen prouinciae Lusitaniae?

$L$ origine sociale des flamines provinciaux de Lusitanie

Antonio Ferreruela Gonzalvo el José Antonio Mínguez Morales, Un nuevo descubrimiento epigráfico romanorrepublicano en el Valle del Ebro

Ségolène Demougin, ConCLusions .

ABRÉVIATIONS

BIBLIOGRAPHIE 


\title{
LOS RECURSOS ECONÓMICOS DE LOS NOTABLES DE LA BÉTICA ।
}

\author{
Antonio CABallos RUfino *
}

Ardua se presenta la tarea de analizar una temática como la expresada por el título, dada la complejidad y magnitud de las cuestiones a tratar, donde se aúnan las dificultades conceptuales e interpretativas a la complejidad hermenéutica de una documentación escasa y heterogénea. Aquí me voy a limitar a exponer algunos planteamientos teóricos y a diseñar una imagen general, que pretende sea suficientemente ilustradora de los argumentos básicos de la temática definida por el título, excesivamente ambicioso. del trabajo. De ninguna manera pretendo aquí la exhaustividad. En todo caso los resultados no pueden considerarse sino siempre provisionales, máxime cuando distan de estar fijados los correspondientes repertorios prosopográficos, lastrados tanto por los problemas de identificación estatutaria como, sobre todo, por las cuestiones derivadas de la certificación del origen ${ }^{2}$, y. a la par. las aportaciones de la epigrafía anfórica en este terreno. por mucho que se puedan intuir como fructíferas, no han hecho sino empezar. En este último terreno la hermenéutica tiene que recorrer un largo camino plagado de escollos debidos a las limitaciones documentales y a las dificultades interpretativas de los registros, tanto los impresos como los rotulados.

Nos sigue pareciendo fórmula más idónca la de enfocar el estudio con principios y métodos básicamente prosopográficos. Ello exige definir las reglas de inclusión-exclusión en el análisis. Pero aquí es donde el término "notable", si bien elocuente, se muestra técnicamente poco preciso al enfrentarse con la multiplicidad de criterios estatutarios que determinan la posición social en Roma. Y, a este respecto, "notable" y "rico" son conceptos que, si bien interrelacionados, corresponden a niveles conceptuales diversos.

Si nos detenemos en el primero de ellos, "notable", nos encontramos con un proceso que ha desembocado en una casi inversión de significados entre los términos latinos nobilis/ notabilis, y los derivados etimológicos españoles "noble/notable" ; complicado con la incorporación de al menos otros dos vocablos de etimología dispar, griega y francesa, que en español disponen de campos semánticos concomitantes: "aristocracia" y "elite". Sobre el sentido originario de los términos latinos nobilis y nobilitas ha tratado muy recientement M. A. Levi ${ }^{3}$. Como recoge éste, el término nobilis y su derivado, la nobilitas, hacen referencia a la notoriedad personal fundamentada en el prestigio y la riqueza, sin contaminación política, sin prefijar estatutariamente, ni presuponer la adscripción en ningún estrato social determinado. Estos "nobiles", en su acepción originaria latina, esto es, los que

* Universidad de Sevilla. España.

1 Este estudio ha sido elaborado en el marco del Proyecto de Investigación "Los procesos de promoción supraprovincial y la romanización de las provincias hispanas (siglos 1-III p.C.)" (PB97-0726), financiado por el Programa Sectorial de Promoción General del Conocimiento de la Dirección General de Enseñanza Superior e Investigación Científica del Ministerio de Educación y Ciencia español.

2 Cuestiones sobre las que aquí no entraremos. A título de ejemplo pueden consultarse al respecto nuestros planteamientos en Caballos 1990b. $181-199 ; / d$. 1994. 29-49: Id. 1998a. 123-146: /d. 1999a: Id. 1999b. $103-144$.

3 Levi 1998, 556-559. 
eran conocidos ${ }^{+}$, equivaldrían a "les élites", en su primitivo sentido francés aplicado a la sociedad, esto es, "les élus du monde" ". Sería en época medieval cuando "noble" acabaría designando una categoría social marcada por el exclusivismo del nacimiento.

Atendemos ahora al vocablo latino "notabilis", para llegar al término usado en el título. De nuevo nos encontramos aquí con una divergencia entre la acepción original del término y la que ha llegado a adquirir en el español moderno". En latín "notabilis" es en principio aquél que posee una marca de reconocimiento público ${ }^{7} \mathrm{y}$, por lo tanto, se refiere propiamente a todos aquéllos encuadrados en ordines. A pesar de que la acepción del término, como vemos, sea más genérica. excluiremos aquí del análisis al orden decurional, o, más precisamente, a quienes de entre éstos no hubieran ostentado a la par el anillo ecuestre. El fundamento de esta exclusión es doble. Por una parte criterios de dimensión del estudio y de heterogeneidad documental. Por otra, argumentos derivados de la óptica con la que hemos enfocado el trabajo, a la búsqueda de un mejor conocimiento de los procesos de integración, del que uno de sus exponentes más reveladores es el de la promoción supraprovincial, manifestación de la homologación socioeconómica y la sintonía con los ideales y la política del Estado imperial romano, refrendada oficialmente mediante una concesión estatutaria. Nos interesa específicamente aquí el papel que desempeñan los criterios económicos en esta promoción, que supone la integración en el "uterque ordo", marca externa y sanción pública de la "aceptabilidad". Estatutariamente nos referiremos por tanto a senadores y caballeros. Aquí, por tomar en consideración estos dos criterios, riqueza y sanción juridico-política de la adscripción estatutaria, la heterogeneidad social y funcional de los equites pasa a un segundo plano ${ }^{8}$, además de que, númericamente hablando, serían muy escasos aquellos caballeros de la Bética documentalmente certificados y conocidos por su nombre - que son los que aquí más directamente vamos a considerar - a quienes debiera claramente excluirse de la aristocracia imperial ".

Podemos calificar de sociológicamente "natural" la tendencia a justificar interesadamente la supremacía de las elites, en este caso las romanas. hijas de un dilatado proceso histórico en íntima conexión con el desarrollo y difusión del fenómeno de la urbanización.

$\downarrow$ Oxford Latin Dictionary, s. v nobilis : ...nobilem antiqui pro noto ponebant... Para el término español véase Corominas \& Pascual 1980, s.v "conocer". Del Diccionario de la lengua española. 1992. nos interesan las siguientes acepciones del vocablo "moble" : 1. adj. Preclaro, ilustre, generoso : 2. Principal en cualquier línea ; excelente o aventajado en ella : 3. Dicese de la persona gue por su ilustre nacimiento o por concesión del soberano posee algún título del reino. y por ext. de stis parientes : 5 . Honroso. estimable, como contrapuesto a deshonrado y vil.

5 Sobre los orígenes del término remitimos. e.g., a Bottomore 1995, 5, quiell, desde la referencia a algunas primitivas acepciones genéricas, salta inmediatambnc. como eje de su discurso, a la teoría de las elites de Pareto y Mosca. La Real Academia detine escuetarnente a la elite como "minoría selecta o rectora".

" El Diccionario de la lengua española. 1992, nos aporta las siguientes definiciones del vocablo "notable" de interés aquí : I. adj. Digno de nota. atención o cujdado; 2. Dícese de lo que es grande y sobresaliente. por lo cual se hace reparar en su línea ; 4. m. pl. Personas principales en una localidad o en una colectividad.

Oxford Latin Dicfiomary: s.v. nota y su derivado notabilis. Sólo por extensión esta acepción, especialmente en su derivación romance, ha podido llegar a contaminarse con la precedente de nobilis/noble.

ช Lal nomable djcotomía del estamento ecuestre. por la que queda marcada una cestira entre quienes funcionalmente formaron parte de las clites provinciales, limitándose cstos caballeros a la posesión del anillo ecuestre como símbolo de adscripción estatutaria, y quienes. por el desempeño de procuratelas y prefecturas, formaron parte de la aristocracia imperial. Por nuestra parte también hemos expuesto una más detallada caracteriación de este tenómeno y descrito algunas de sus implicaciones sociales y políticas en Caballos Rufino $1999 \mathrm{~b}, 103-1+4$. 
que se fundamentaría en una pretendida (y asumida) mayor capacitación o virtud puesta al servicio del colectivo mediante el desempeño de determinadas funciones, que son a la par el medio por el que estas elites exteriorizaban su supremacía.

Por lo mismo. su posición social y sus privilegios políticos necesitaban justificarse mediante la apariencia de la existencia de una contraprestación. un precio a esta supremacía, fundamento de una oficial valoración positiva de su papel. Frente a estas consideraciones, la postura del historiador difícilmente puede mantenerse en un estadio de aséptico equilibrio. alejado a la par tanto de la apología como de un forzado y mecanicista "intento de desenmascaramiento". En estas condiciones una salida asumible, por la que habitualmente se ha decantado la investigación, es por la de analizar el proceso de la promoción hasta el logro de la integración en la aristocracia imperial como consecuencia, tras la previa y necesaria aceptación de los ideales tradicionales del Imperio romano por los grupos de la población provincial que rigieron sus ciudades, de la reunión de una serie de requisitos, entre ellos obviamente los económicos.

De estos requisitos, algunos, como la riqueza, evidencian situaciones de hecho: otros se basan en argumentos de carácter jurídico, político y familiar, generadores de múltiples niveles de adscripción estututaria. Así resultan dos principios que, en el caso romano. debemos tener en cuenta a la hora de estudiar la promoción:

1. La sanción legal de la desigualdad social, por lo que las situaciones sociales se ven de hecho interferidas por consideraciones de carácter estatutario.

2. La multiplicidad de criterios que, clasificando desde fuera a los individuos, condicionan la posición social.

Una aplicación mecanicista de esta doble evidencia. alimentada por esquemas teóricos excesivamente rígidos, podría desembocar en la comprensión del proceso de la promoción como resultado de la mera reunión de una serie de requisitos multiestatutarios. El análisis comparativo nos permitiría así establecer de forma teórica cuáles serían los rasgos que oficialmente se consideraban propios y específicos de un nivel de adscripción y merecedores de consideración social como modelo, asimismo oficial, de comportamiento. Un primer resultado ha sido la obtención de un listado de "excelsitudes". Se podría entender así que la mera reunión de estas "virtudes" serían garantía de promoción, y que. a mayor excelsitud, mayor rango. Pero la evidencia se encarga de demostrarnos que la realidad no sigue principios tan mecánicos.

En primer lugar, existe una gradación en los múltiples y heterogéneos criterios que fundamentan la promoción. a la par variable y modificándose a lo largo de los tiempos. En segundo lugar, junto a los argumentos "oficiales", no podemos obviar el papel jugado tanto por la suerte, la fortuna. como por el oportunismo que supone el aprovechamiento de circunstancias propicias. Como resultado de todo ello se deriva que la promoción no puede limitarse a ser mero resultado de una tarea indiscriminada de "coleccionismo", completando niveles máximos de consideración multiestatutaria. No es una cuestión de cantidad. La

9) De entre los caballeros de la Bética repertoriados en Caballos 1995, 289-343, aparte de los praef. fabr: $\left(n^{\circ} 14,15,22.31 .35\right.$ y 36), de identiticación complicada. sólo se puede certilicar como exclusivo miembro de la elite provincial (sin haber desempeñado funciones ecuestres) a $D$. Imius Melimus ( $n^{\circ} 13$ ) : y de nuevo volvemos a repetir la excepcionalidad de quien se ha conservado huella epigráfica precisamente por tratarse. como apropiadamente se indica en la inscripción que lo conmemora (CIL. II. 1955). del eques Romanus ex ciuitate Carrininana primus fuctus. 
promoción es la recompensa de los más aptos, de los mejor situados en una coyuntura histórica concreta, no de los que podríamos calificar escuetamente como "los mejores". Por ello, para calibrar la actitud para la promoción, cuentan la sensibilidad para aprovechar la coyuntura, la flexibilidad para amoldarse a las exigencias del poder en cada circunstancia concreta, las relaciones personales y las recomendaciones, aquellas "clarae et nobiles amicitiae" que propiciaron la promoción personal de Lacilius ${ }^{10}$.

El mismo Lucio Anneo Séneca indirectamente nos permite conocer, con el símil militar de quien se enfrenta en primera fila a los peligros, no sólo cuáles eran considerados los argumentos fundamentales de excelsitud, sino también el valor de la imagen pública, manifestada en el comportamiento: Quo quisque honestior genere fama patrimonio est, hoc se fortius gerat, menor in prima acie alos ordines stare "1. El honor, la dignidad, fundamento de influencia, autoridad y poder, se basan así en el prestigio de la estirpe, la fama. fruto de la actitud. reforzada tanto con las relaciones de amicitia, como con el respaldo social de las clientelas, y, ¡como no!, una fortuna sin mancha, esto es, una riqueza basada en argumentos patrimoniales.

Para un mejor conocimiento del fenómeno de la promoción, resulta por lo tanto de prioritario interés conocer también los fundamentos económicos de la consideración y el ascenso social, así como el ámbito geográfico de la implantación local de los bienes de estas elites imperiales de origen bético. Ello nos permitirá establecer si el reclutamiento y designación de estos caballeros y senadores provinciales era meramente debido a factores y necesidades políticas, o bien si a la par reflejaba, y en qué medida. la evolución de las condiciones económicas y sociales de su entorno, de la que sería su patria provincial. Complementariamente habría que analizar las repercusiones, tanto personales como familiares, de la promoción estatutaria de los provinciales, que tendría también su faceta económica, pero no sólo sobre los propios promovidos y sus allegados, sino asimismo sobre sus comunidades de origen. Si, por una parte, se constata un proceso de modificación, transformación o, en su caso, disolución paulatina de los vínculos de los promovidos con sus localidades de origen, de innegables repercusiones para la propia provincia, también resulta de interés el estudio del establecimiento de nuevos vínculos personales y ambientales como consecuencia de la promoción. por este orden, con Roma. Italia y las provincias.

Un punto de partida teórico se impone. En una sociedad como la romana los recursos patrimoniales son conceptuados, no como un fin en sí, sino como un medio y garantía de un tipo de vida digna, adecuada a la funcionalidad política y social de las elites. Por ello mismo no todo tipo de enriquecimiento ni actividad es lícito 12. Prueba del carácter no exclusivo de la riqueza es que la simple posesión de los recursos económicos. aunque la posibilita. no garantiza la promoción. Igualmente un mayor volumen de recursos no aporta en la misma proporción mayores garantías de promoción. La riçueza, para convertirse en fundamento de promoción estatutaria, debe soportar el paso del tiempo, que, además. tiene el efecto de diluir procedimientos no muy confesables en la adquisición de los recursos patrimoniales.

10. Séneca. Ep., 19.3.

11 Séneca. Dial., 2.19.3.6 (ad Serenum, de consfantia sapientis) : "Cuanto más honomable es alguien por estirpe, fama y patrimonio. tanto más valerosamente se comporta, teniendo presente que en primera línea están los más elevados ordines".

12 Lo que no es óbice para la existencia de intinidad de fómulas de obvial estas prohibiciones, sobre todo por el recurso a personas interpuestas. argucia que no hace sino dificular aún más el análisis del fenómeno. 
La necesidad del acompasamiento a la naturaleza y los ritmos que ésta genera como guía de las actitudes económicas, nos muestra hasta qué punto estos planteamientos teóricos romanos sobre la economía divergen de los propios de una economía de mercado, y en qué medida estas sospechas hacia un progreso, digamos, "indiscriminado" imponen un freno en la práctica al desarrollo de comportamientos capitalistas. Esta consideración peyorativa de todo enriquecimiento basado en fórmulas meramente capitalistas, estas sospechas ante una economía liberada de ataduras ideológicas y morales, son sentidas muy sensiblemente en todo lo que atañe a los procesos de promoción. Por una parte se justifica la desigualdad en la situación económica de los individuos, y por ende su desigual papel político, como resultado de la voluntad divina. Por otra se explica que la generosidad como fómula de aceptación social sea uno de los fundamentos esenciales de la promoción. La generosidad no sólo permite tejer una complicada red de dependencias interpersonales, fundamento de poder, sino que, a la par, el evergetismo se convierte así en una fórmula práctica y aparentemente inofensiva de apartar del acceso al poder a los que no gozan de los adecuados recursos económicos. Estos principios económicos, propios del régimen de la ciudad, sólo progresiva y muy paulatinamente se fueron diluyendo al socaire de la sustitución de las fórmulas políticas por las suprapolíticas o estatales. El proceso se fue consolidando precisamente a lo largo del Imperio. cuando las tensiones entre esta arcaica ideología económica y las necesidades y posibilidades surgidas de un Estado complejo se hicieron más evidentes. La solución vino en una línea muy conforme a los propios comportamientos romanos: pragmáticamente se mantuvieron las apariencias de los viejos modelos ideológicos, mientras que en la práctica se fueron buscando vías para llevar a cabo una economía capitalista sin dañar los principios. Se dejaba que el tiempo, por sí sólo, sin excesivos forzamientos y por un proceso de paulatina adaptación, fuera limando las incongruencias generadas. La carencia de una fundamentación "constitucional" evitaba la necesidad de la generación de modelos teóricos que pudieran ser tildados de excesivamente rupturistas. Como resultado, los parámetros mentales acerca de la economía y sus repercusiones prácticas en actitudes y comportamientos económicos, fueron igualmente modificándose de forma paulatina, y, lo que aquí concretamente más nos interesa, los argumentos económicos de la promoción no fueron tampoco ajenos a estos cambios.

Para un mejor conocimiento de los procesos de movilidad ascensional, fundamento básico de cohesión en el Estado imperial romano, resultaría altamente interesante tener información acerca de todos los pormenores y fórmulas de enriquecimiento de las elites provinciales, así como de la evolución experimentada por éstas a lo largo del Imperio. Pero en poquísimas ocasiones ello es posible. Lo que de ninguna manera nos debe a priori extrañar. En la mayoría de los casos el proceso de lenta formación de una fortuna familiar, como fórmula de capacitación económica que haga posible la promoción. nos resulta por completo desconocido. Lo normal es que sólo observemos sus últimos estadios, o incluso que sólo podamos remitimos precisamente al personaje promovido, resultando sus antecedentes económicos una total incógnita.

La documentación nos permite, eso sí con carácter general y con escasas posibilidades de cuantificación, cnumerar los argumentos más comúnmente aducidos como fórmula de progreso económico. Las fórmulas del lucro tienen una etiologia plural. Algunas 
aportan argumentos de promoción y, bien a la par, bien como resultado de aquélla. posibilidades de enriquecimiento. Me estoy refiriendo al servicio al ejército, que fue una vía siempre expedita, aunque abierta a la promoción sólo para una corta minoría. También a la formación oratoria, más exclusiva, que las fuentes evidencian como el recurso más operativo y fundamento de promoción a comienzos del Imperio. Y ésta con una doble virtualidad, si, por una parte, permite ampliar el marco de las relaciones interpersonales incorporando a miembros de la nobilitas, por otra significa una capacitación en la gestión especializada de los asuntos públicos. De aquí al efectivo nombramiento administrativo mediaba en muchos casos sólo un paso. que el poder, por propia operatividad e interés, habitualmente no habría de dudar en hacer realidad. Los lazos familiares y su ampliación por la fórmula de los parentescos, así como las vinculaciones sociales, amicitia y clientelae, pueden aportar las correspondientes repercusiones económicas. Herencias, donaciones y obsequium son sus fórmulas. También. indirectamente, el aprovechamiento de los recursos obtenidos por esta vía, como las explotaciones agrícolas y sus actividades complementarias y subordinadas. Por aquí los rendimientos del trabajo agrícola nunca podrían adquirir dimensión exponencial. Sí, por el contrario. las derivadas de las contratas públicas, tanto minas, como arrendamiento de servicios públicos, o bien de la recaudación de impuestos. El encuadramiento en societates publicanorum se muestra en muchos casos la fórmula ; la misma que permite mayores beneficios, por escala, a las sociedades mercantiles. Junto al comercio, actividades industriales o artesanales a gran escala posibilitan rentabilidades operativas a efectos de promoción, mientras no se sobrepasen los criterios ideológicos de la aceptabilidad.

Como ya argumentamos en otra ocasión, nos resulta imposible siquiera acercarnos a un análisis porcentual de las posibilidades de ascenso económico. Es el propio lento ritmo del enriquecimiento, dadas las posibilidades económicas de la época, el que permite acompasar la marcha del progresivo ascenso familiar con la obtención de una dignitas esquiva a la mayoría. En muchos casos habría que reconvertir los ingresos obtenidos para transformar la actividad económica en criterio de honorabilidad. Sólo el tiempo, medido en generaciones, podría expiar el recurso a fórmulas de enriquecimiento estigmatizadoras. El logro económico, al que debían acompañar los citados criterios estatutarios, habría de pasar la prueba de la aceptabilidad. a modo de proceso de cooptación por los componentes de los ordines. Tanto el dilatado camino que habitualmente debía ser recorrido, como los fracasos en ese lento discurrir a lo largo de generaciones no suelen dejar huella documental. Las excepciones no hacen sino evidenciarnos la parquedad con la que la fortuna debió exteriorizarse.

Es aquí donde vuelve a resultar sano aludir a la cuestión de la capacidad informativa de las fuentes disponibles, a la necesidad de no considerarlas como algo absoluto. Se impone una valoración de la evidencia disponible, que permita unas idóneas posibilidades de extrapolación posterior. La heterogeneidad de las fuentes y las dificultades comparativas que de ello se derivan, deben ser a priori asumidas para evitar, operando con magnitudes diferentes. juegos incongruentes y extrapolaciones viciadas. El riesgo de primar lo documentado, por este mero hecho de haberse transmitido hasta nosotros, se hace así evidente. 
La mayoría de las actividades económicas no dejan huella documental perdurable. Si en su momento las generaron. éstas, por su propia especificidad y razones de funcionalidad y operatividad, solían ser recogidas en soportes no perdurables. Por el contrario, en la mayoría de los casos y salvo circunstancias excepcionales que así lo justifiquen, el recurso al soporte epigráfico se muestra una opción incongruente. La operatividad de éste, habitualmente limitaoa al mundo municipal, se circunscribe por ello mismo a un marco cronológico restringido. concentrándose sobre todo desde los Julio-Claudios a los Severos, haciendo con ello inviable el recurso inmediato a los análisis diacrónicos con posibilidad comparativa al margen de este marco, y exigiendo, en todo caso, el recurso a índices correctores, con toda la carga de aproximación y aleatoriedad que ello puede acarrear. La información de carácter económico es habitualmente ajena a la funcionalidad de la documentación epigráfica. La mención de actividades públicas, homenajes locales. relaciones familiares y de amistad o vinculaciones de dependencia sólo indirectamente nos aportan datos de significación cconómica, identificación de propiedades, dispersión de bienes, actividades evergéticas... Sobre las posibilidades informativas de la epigrafía anfórica ya nos pronunciamos al comienzo de este trabajo. Mucho se espera de ella, hasta casi creerla panacea universal. Pero, al margen de que aún carecemos de repertorios exhaustivos ${ }^{13}$, los datos que de ella se derivan. no sólo distan de permitir una valoración inmediata a los efectos que aquí nos interesan, sino que. en muchas ocasiones, por exceso de confianza pueden conducirnos a hipótesis erróneas ${ }^{4}$. Por el contrario, podemos congratularnos, no sólo del esfuerzo de recopilación documental que se está desarrollando en la actualidad en las tradicionales áreas olivareras del Bajo Valle del Guadalquivir, sino la incorporación de áreas de trabajo nuevas y con muy prometedoras expectativas en relación con otras actividades productivas ${ }^{15}$. Por su parte los estudios sobre ladrillos y fistulae, que nos permiten la identificación de propiedades, actividades públicas y producción industrial, son mucho más limitados, no generando repertorios amplios, salvo en lo que a la Urbe se refiere.

Por tanto, sólo las fuentes literarias nos permiten en ocasiones información que, por su exclusivismo, se vuelven doblemente valiosas, además de por lo prolijas, por las calificaciones morales que aportan sobre los procedimientos de promoción. El conocimiento que tenemos sobre la trayectoria de los Annciei, tanto a través de las obras de los dos Sénecas y de Lucano, como del propio Tácito, se puede considerar excepcional. Pero tampoco están genéricamente libres de un inconveniente doble, en lo que aquí nos interesa. Primero, por los problemas interpretativos que aporta la carga de subjetividad que contienen. Segundo. por las dificultades en rastrear generacionalmente el origen último de las fortunas. Porque habitualmente no hay deseo, o no interesa dejar constancia de ello, incluso con el presumible

13 Amén de la limitación cronológica, derivada de circunstancias estructurales del Testaccio y de las posibilidades arqueológicas, que supone el conocimiento casi exclusivo de tihli picri correspondientes a una etapa bien avanzada del Imperio. Información actualizada sobre los continuos avances en estas actuaciones en el Testaccio llevadas a cabo por el equipo comandado ahora por J. M. Blázquez y J. Remesal en http://www.ub.es/ CEIPAC/ceipac.html.

14 Un ejemplo baste. En su momento Chic asignaba las marcas de la figlina Virginensia ("Villar de Brenes". Sevilla) y de la próxima "Cruz del Verde" que contenían las siglas P.A.H. a P(ublius) A(elius) A(drianus) (cf. Caballos 1990a, 42). Hoy una nueva estampilla de la misma serie contiene P.AN. ¡Se trataría de un Amiats y no de un Aelias! Cf. Chic 1992, I-2 I. Lo mismo del Attiamus documentado en rituli del Testaccio (cf. Caballos 1990a, 34) : no se trata de un Acilius. sino presumiblemente de un Annius Attianus.

15 Un primer fruto es la espléndida monografía de García Vargas 1998. 
expediente del recurso al "filtro" de las informaciones ideológicamente no convenientes. Si el acceso al poder imperial, con las repercusiones informativas que ello supone. añadido a las aportaciones que está brindando en los últimos tiempos la epigrafía, nos está permitiendo conocer razonablemente bien la evolución de los Ulpii Traiani, sólo podemos retrotraernos al pasado cuando ello convino, permitiéndonos llegar hasta los que lograron alcanzar niveles decurionales superiores, como resultado de la necesidad de exteriorizar epigráficamente un estatuto local privilegiado en época augustea. Nada se nos dice de cómo se produjo la inmigración familiar desde Italia, ni cuál es la extracción de ésta, ni tampoco cuáles las fórmulas de su enriquecimiento. Por mucho que puedan contar con adecuado fundamento, pertenecen al reino de la suposición la adscripción a las clientelas pompeyanas y las presumibles actividades fundiarias. Desconocemos qué grado de tradición contaba el recurso a la vía militar en la familia.

Pasando ahora a aportaciones de carácter más concreto, comenzaremos por la descripción, a partir de ejemplos escogidos, de los más significativos fundamentos de la riqueza de los equites de la Bética expresados en la documentación. Ya nos hemos referido a la heterogeneidad en la composición del ordo. Pero también al hecho de que. por la funcionalidad de la fuente epigráfica como idóneo expediente para la expresión ideológica. este inconveniente se minimiza al haber ejercido la mayoría de los caballeros documentados en la provincia funciones ecuestres. La tipología de las carreras de los caballeros que incluimos en nuestro catálogo nos permite identificar a 9 ó 10 procuradores o prefectos ecuestres, pero, sobre todo, hay que contar con que una mayoría - más de la mitad del total desempeñó actividades ligadas a la milicia, en concreto un total de 22 . junto a los que habría que considerar 6 praefecti fabrum. Que sepamos, al menos 4 de entre quienes iniciaron una carrera militar de rango ecuestre. desempeñaron con posterioridad funciones administrativas como procuradores o prefectos ${ }^{16}$.

Las fuentes disponibles nos permiten contar con formas de identificación externa de la riqueza, lo que nos puede servir de indicio para analizar la composición de las fortunas; siendo mucho más difícil conocer en concreto la génesis de éstas. En pocas circunstancias conocemos los fundamentos de la riqueza de los equites béticos, que en ocasiones, a tenor de los indicios de que disponemos, debieron superar con creces el censo mínimo exigido para el ingreso en el ordo ${ }^{17}$. Son de destacar las propiedades que el tío de Columela tenía en la región de Cádiz ${ }^{18}$. C. Rocius Rocianus se habría dedicado a la producción aceitera ${ }^{19}$. De otras actividades en la provincia conocemos a través de la epigrafía las múltiples dedicaciones que algunos caballeros llevaron a cabo: $M$. Comelius Noua/n/tus Baebius Balbus un acueducto ${ }^{20}$, el ignotus de Abdera basilicam cum hypaethro epulo dato ${ }^{21}$, lQuintiu?']s Hispanus edificaciones en Obulco ${ }^{22}$, y las donaciones de C. Venaecius

16 Puede consultarse la documentación pertinente en Caballos 1995.

17 El caso. e.g.. de C. Vencecius Veconianas. dedicante de una estatua de oro al la diosa Fortuna. otra de 5 libras a Mercurio. junto con una pátera de una libra y dos basas de plata de 5 libras calda una $(C / L$. II. $2103=$ C/L. $\left.11^{2} / 7.67\right)$.

18 Columela. De r.r., 10.185.2.10.18.

19 Ct. Caballos 1995, 326-328, 11030.

20) CIL. I1. 1614 (Igabrum).

21 CIL. 1I. 1979 y IRAI, 2 y 25.

22 CIL.11. 2129 = CIL. 112/7.97. 
Voconiamus en Vigavo. El poderoso L. Valerius Proculus, que desarrolló una amplísima y muy prestigiosa carrera ecuestre, llegando hasta la cima del cursus como prefecto de la Annona y de Egipto, fue elegido por los malacitanos como patrono ${ }^{23}$.

En cinco casos las fuentes se detienen en hacer menciones especiales. De Clodius Turrinus se nos dice patre splendidissimo, auo diui luli hospite. et pecuniam... et dignitatem quam primam in pronincia Hispania habuit 24. El caso de (L.?) Annaeus Seneca y de su familia es excepcional por la cantidad de documentación de que disponemos ${ }^{25}$. L. Baebius Balbus se encuentra documentado por una inscripción de Castelmadama, junto a Tibur ${ }^{26}$, lugar de amplia concentración posterior de hispanos ${ }^{27}$. D. Lumius Melimus fue eques Romamus ex ciatate Cartimitana primus factus ${ }^{2}$, , mientras que Iunia D.f. Rustica, su hija o su hermana, es mencionada como sacerdos perpetua et prima in municipio Cartimitano. Si bien es pertinente citar también el caso de P. Acilius Attianus, lo conocido de su biografía nos exime de repetir los datos que se extraen del análisis de la Apotelesmática, su trayectoria política y los elementos que lo vinculaban a las familias de los Vlpii y Aelii, así como los testimonios que pueden reflejar su situación económica ${ }^{29}$.

Las inscripciones funerarias nos permiten certificar que al menos nueve de los personajes incluidos en el Catálogo murieron en la provincia, lo que sería usual para la mayoría, especialmente en el caso de que las funciones administrativas o militares no los hubiesen mantenido por mucho tiempo fuera de la Bética. En doce ocasiones tenemos constancia del homenaje recibido en comunidades urbanas de la provincia ${ }^{30}$, siendo en el caso de T. Mercello Persinus Marius dos las ciudades que decidieron honrarlo, Corduba y un yacimiento que tal vez corresponda a la antigua Segida Augurina ${ }^{31}$.

De dos conocidos personajes tenemos certificada la existencia de propiedades en Italia, de L. Iunius Moderatus Columella ${ }^{32}$ y de $P$. Acilius Attianus. ${ }^{33}$, como también puede ser intuido para otros ${ }^{34}$. Creemos significativo ser̃alar la precisa vinculación con Praeneste tanto de $P$. Acilius Atriamus como de los dos hermanos Valerii, C. Valerius Florinus y $L$. Valerius Proculus ${ }^{35}$. Estos tres personajes, como consecuencia del rango, prestigio, poder e influencia alcanzados, necesariamente habrían extendido mucho su ámbito de actividades. Así si C. Valerius Florimus murió fuera de Hispania, la Valeria L.f. Procula, casada con el ilustre T. Pontius Sabinus de Ferentinum (en el Lacio, junto a la Vía Latina), verosímilmente habría sido hermana suya. No hace falta insistir de nuevo en la archiconocida carrera de Attiano.

23 CIL. II. $1970:$ CIL. II. $1971:$ CLL.VI, 1002 y CIL. XIV. 2957.

24 Séneca. Contr., 10, pr. 16.

25 Caballos 1995, 295-297. n० 4, 298, n 6, 299-301. $n^{\circ} 8$.

26 CIL, XIV, 3515.

27 Syme 1982-83,241-263.

28 CIL. II. 1955 (Cartima).

29 Cf. Caballos 1984, 237-251; cf. Caballos 1990a, 31-38. n 5.

30 Cf. Caballos 1990a. $n^{\circ} 3,12-13,20,24,26,28,30-31,34-36$.

$31 C$ CL. II, $2226=C / L$. II $2 / 7.311$ : Stylow 1988. $119-120$ y $150=H E$ p, 2, 1990. $345=A E .1988 .739=$ CIL. II $2 / 5,1296$.

32 CIL. IX. $235=I L S, 2923$.

33 CIL. XIV, 3039. En la isla de Elba se le documenta en una fístula plúmbea. así como en una inscripción a Hércules (CIL. XI, $2607:$ CIL. XI. $7248=A E, 1903.325=$ ILS, 8999).

34 E.g., para los Anncei.

35 CIL. XIV. 2957. 
De un porcentaje de en torno al $20 \%$ del total de caballeros de la Bética conocidos tenemos documentado que llegaron a tener su domicilio en Roma ${ }^{36}$. Salvo en el caso de $P$. Acilius Atrianus, justificado en función del nivel alcanzado, y del tardío M. Vibius Maternus, de época de Septimio Severo, que por ello mismo refleja en Roma epigráficamente la origo (Ilurensis) ${ }^{37}$, el resto de los personajes corresponden a una fecha temprana. Efectivamente. todos los restantes pertenecen a época julio-claudia. Por entonces las inquietudes por el logro de la promoción tendrían más amplios cauces y posibilidades de éxito si previamente hubiera tenido lugar una emigración a Roma, objetivo de los afanes de estos provinciales ; lo que no tendría por qué desembocar de forma definitiva en una pérdida total de los lazos con sus comunidades. La documentación se encarga de certificar el mantenimiento de estos lazos, siendo el caso de los Amaei paradigmático, pero de ninguna manera único cn nucstras fuentes. Del primero de los personajes del Catálogo, Clodius Timrinus, se dice expresamente - ya lo vimos - "et pecuniam... et dignitatem quam primam in prouincia Hispania habuit" 38.

No mucho más explícita es la información que, acerca de los fundamentos de la riqueza de los senadores originarios de la Bética. podemos extraer de la documentación hasta ahora disponible. En un trabajo anterior ${ }^{39}$ dividiamos los senadores estudiados entre los que, con criterios restrictivos, contaban con un más plausible origen bético y aquellos cuyo origen bético. con un margen muy amplio, era inseguro o sólo probable. El primer grupo contaba con un total de cuarenta y siete senadores, y el segundo. los de origen bético más incierto, con sesenta. Incluso a esta cifra total se podían añadir hasta cinco personajes más, ciertamente hispanos pero cuya concreta adscripción provincial no está asegurada. Ahora. a partir del catálogo prosopográfico contenido en el primer volumen de nuestra monografía sobre los senadores hispanorromanos ${ }^{+0}$, tomamos en consideración hasta un total de 92 senadores o, al menos, miembros del ordo senatorius cuyo origen con mayor o menor probabilidad pudo haber estado en la Bética.

Si hablamos de la Bética, el aceite se nos manifiesta como, junto a la minería, un argumento económico esencial y que marca rotundamente a este respecto la especificidad de esta provincia, especialmente si nos estamos refiriendo a la época post-neroniana ${ }^{4}$. Vinculados con la producción y el comercio del aceite, de forma directa o indirecta. nos aparecen algunos personajes de rango senatorio. Porcentualmente son pocos, en torno a un $5 \%$ del total, lo que no debe extrañarnos excesivamente, tanto por cuestiones derivadas del azar de la transmisión documental, como por la circunscripción de los tituli picti conocidos a una época relativamente breve y bien avanzado el Imperio. así como a las múltiples formas alternativas en que. de forma indirecta, puede expresarse esa vinculación económica de los senadores con la explotación del olivar bético. La identidad onomástica es un argumento muy inseguro, que no nos permite expresar deducciones fiables. Es por ejemplo el caso de los

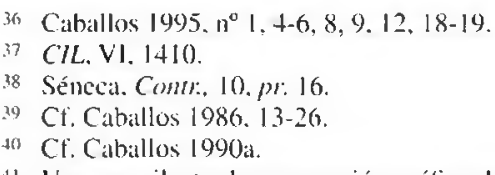

+1 Una muy ilustradora expresión gráfica de la evolución de las exportaciones de aceite procedente de la Bética en García Vargas 1998. 399, fig. 81. Sobre la dinámica económica general de la Bética y el papel en ésta de la producción y el comercio del aceite véase Chic 1983. 163-182;/d. 1991, 277-297:/d1. 1995.95-128: así como últimamente, lambién del mismo. Id. 1999. 33-59. 
mercatores de aceite con el mismo gentilicio de $M$. Aponius Satuminus, senador de época tiberio-claudiana ${ }^{42}$. Sobre suelo mucho más firme pisamos si nos referimos al paradigmático caso de $M$. Ammius Verus, cuyas explotaciones llevan el nombre de Germaniana, Nacuiana, Quintunensia, y opus Salarese ${ }^{4.3}$. El caso de $Q$. Comelius Proculus, cuyo nombre completo era L. Stertinius Quintilianus Acilius Strabo Q. Cornelius Rusticus Apronius Senecio Proculus ${ }^{+4}$. cónsul en el 146 y proconsul de Asia probablemente en 161/162. y el de su hijo, laınbién $Q$. Comelius Senecio Proculus, éste legado pretorio en Asia, cargo en cuyo desempeño falleció ${ }^{45}$, es muy significativo. Por criterios onomásticos, tanto los Stertinii, como los Cornelii pudieron haber estado vinculados con possessores documentados por la epigrafía anfórica. A la zona de control de Astigi, concretamente al yacimiento de "La Sesenta" +6 , pertenecen marcas con una difusión bastante amplia y las leyendas Esterti Paulli, C. Ster(tini) Paullini, Eut(yches) C. Ster(rini) P(aullini) s(eruus) (?) ${ }^{47}$, datadas entre el 90 y el 140 p.C. ${ }^{48}$. St (ertimi) Ca(-.-) ${ }^{49}$ y $G$. S(tertini) Api(lius?), datada esta última en el siglo ${ }^{50}$. En relación con el gentilicio Comelius está documentado un productor oleario de nombre Cornelius Proculus ${ }^{51}$. Una identificación. bien con alguno de los anteriores, bien con alguien próximo, resulta muy sugerente. Un rótulo pintado de un ánfora producida en la figlina "La Catria" (Lora del Río. Sevilla), con marca impresa $S N R{ }^{52}$ y controlada fiscalmente en Astigi con fecha del 154, menciona como ámbito de producción el fundus Aelianum ${ }^{53}$....ELIANVM, por tanto presumiblemente /A Jelianum, es lo que registra un titulus pictus incompleto del $149^{5+}$. ¿Qué margen de verosimilitud queda para una vinculación con los Aelii italicenses? Por último, de acuerdo con una ordenación cronológica, remitimos al caso de la familia iliberritana de los P. Comelii Anullini. El padre, cos. suff. hacia el 175 y cos. $I /$ el $199^{55}$, y el hijo homónimo, cónsul ordinario el $216^{56}$. Del fundus Paternus, con control fiscal de Hispalis, tenemos documentado como productor en los años 140-145 a un Anullints ${ }^{57}$. Aún sin abandonar el terreno de la hipótesis, cabría plantear una teórica vinculación con la familia de los senadores iliberritanos.

Sin dejar este mundo de la economía oleícola, si nos acercamos al ámbito de la producción anforaria, también las marcas impresas sobre el barro permiten adelantar, si en

42 Cf. Caballos $1990 \mathrm{a}, 75, \mathrm{n}^{\circ} 36$.

43 CIL. XV.245 (figl. Germ., año 135) : CIL, XV. 246 (figl. Germ., año 135) ; CIL. XV, 344 (figl. Nacuian., año 121): CIL. XV. 453 (praed.Quint., año 123); CIL. XV, 454 (id.) ; CII. XV. 455 (praed. Quint.. año 134) : CIL. XV. 478 (opus Salarese. c. 123): CIL. XV. 481 (id.): CIL. XV. 799 (praced. Quim., it. 123): ClL. XV. 800)(id.): CIL. XV, 805 (id.) : CIL. XV. 806 (id.) : CIL. XV. 807 (praed. Quint.. épocá de Adriano) y CIL. XV. 808 (id.).

44 Cf. Caballos 1990a, 106-108, $n^{\circ} 53$.

45 Cf. Caballos 1990a, 113-114, no 57.

46 Ponsich 1979, 62, $\mathrm{n}^{\circ} 128$ : Chic 1985. 55-56. El yacimiento, correspondiente a una villa rustica. se encuentra en la ribera derecha de la denominada "Madre Vieja" (orilla antigua dol Guadalquivir), frente al pueblo de Villaverde del Río (Sevilla), y sus coordenadas son 4478/342'2. Cf. Chic. 1995. 102.

47 Esta intervención de un personaje de rango servil resulta sumamente ilustradora.

48 Callender 1965, 116. n० 485 ; cf. CIL. XV. 3193 y 3194.

49 Ibid. $1965.253, \mathrm{n}^{\circ} 1671$.

50 bid., $114, n^{\circ} 469$.

s) CIL. X, 4274.

52 CIL.XV. 4294.

53 Chic 1988.79.

54 CIL. XV, 4243. Cf. Chic 1988, 87.

5 Cf. Caballos 1990a. 99-101. $n^{\circ} 48$.

56 Cf. Caballos 1990a, 101-102. n⿳⺈ 49.

57 CIL. XV. 4282. 
muchos casos no certidumbres, sí al menos sugerencias. Primero, cronológicamente hablando, L Antistius Rusticus, para lo que aprovechamos la información recogida de antemano ${ }^{58}$. Ya de antiguo eran conocidas las marcas $L$. AT., L. AT. RV. y L. AT. RVS., una sobre un ánfora Dressel 20, lo que la fecha a mediados del siglo I p.C. Las halladas en Port Vendres II fueron interpretadas desarrollando L(uci) At(ti?/-iti?) Rustici${ }^{54}$, aunque tal nombre no está documentado en ningún lugar. Callender, por el contrario, desarrolló $L$. Ant(istiuss) Rus(ticus) ${ }^{60}$. A favor de esta posibilidad hay que argumentar que. aunque no se halla documentado el nexo $A N T$, sino sólo $A T$, no se puede excluir terminantemente una abreviatura junto al nexo, por lo que las marcas buenamente podrían referirse precisamente a un Lucius Antistius Rusticus. Otra cosal es que, incluso de confirmarse esta suposición, en absoluto quedaría demostrada la vinculación directa con cl cos. suff. del 90, y para ello sería necesario contar con la correspondiente argumentación. Complementariamente ANTISTIA(NVM) es, asimismo, el nombre de un fundus que aparece en un ánfora olearia datada probablemente a mediados del siglo II p.C. ${ }^{61}$.

La mujer del senador hispano L. Antistius Rusticus se llamaba Mummia Nigrina, presumiblemente emparentada con el cónsul L. Mummius Niger Q. Valerius Vegetus, también hispano 62. La vinculación con los senadores P. Mummius Sisenna, cos. ord. en el 133, y su hijo P. Mummius Sisenna Rutilianus, cos. sufff. en el $146^{63}$, además de por criterios onomásticos, se refuerza por argumentos económicos. Al centro alfarero de "La Catria", en la orilla izquierda del río Guadalquivir y en las proximidades de Axati (Lora del Río, Sevilla), corresponde la marca de ánforas olearias SISEN. datada en época claudia y con una amplia difusión por todo el Imperio ${ }^{\text {th }}$. Pero es que de ese mismo yacimiento proceden las marcas $Q$. ANT. $R$., de la segunda mitad del siglo I, que han sido interpretadas leyendo $Q$. Ant(onius) $R$ (uga? ) ${ }^{65}$. ¿Por qué no podría tratarse de un $Q$. Ant(istius) R(usticus), teniendo en cuenta el matrimonio entre Mummia Nigrina y L. Antistius Rusticus? 66

Los poliónimos de los miembros de la familia de los Mummii Nigri, cuyo paradigma es $L$. Mummius Niger $Q$. Valerius Vegetus Seuerinus Caucidius Tertullus ${ }^{67}$, también aportan información de carácter económico. Éstos serían herederos, no sólo del nombre, sino también de al menos parte de la fortuna de aquellas familias senatoriales que aparecen en la nomenclatura. Concretamente habrian sido propietarios del Kalendarium Vegetianum, fundación de la que conocemos cuatro procuratores Augusti per Baeticam ad Kalendarium Vegetiantum 68 , encargados de su administración en la Bética tras haber pasado a ser propiedad del fisco hacia el año 160 p.C. ${ }^{69}$.

58 Cf. Caballos 1990a. 69-72. $n^{\circ} 34$.

59 Colls et al. 1977.31.

60 Callender 1965, $\mathrm{n}^{\circ} 803$

(1) Liou 1987, F 89 y Chic 1988. 79.

62 Cf. Caballos 1990a. 231-235. n 129 B (cf. también 129 A).

6.3 Cf. Caballos 1990a. 236-237. n० 131 y $237-239.10^{\circ} 132$.

b4 Chic 1985,65

as $\mathrm{Id}$.

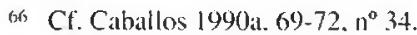

67 Cf. Cáballos 1990a, 231-235. 110 129 B.

$68 C L L$. Il, $1085=I L S, 1406: C / L$, II. $2029=/ L S, 1405: A E, 1956.123$ y AE. 1978, 400. Cf. Ojeda 1993,

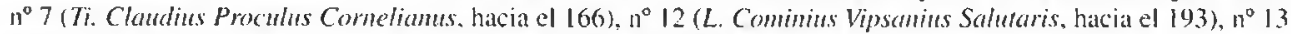
(P. Magnius Rufus Magoniamas. entre el 185 y el 195) y $11^{\circ} 15$ (M. Lucretius Luliamus, en época de Septimio Severo).

69) Según Pflaum (1960-1961).633-638, ad n² 236, en época de Marco Aurelio. según Lonas \& Síéz, 1981, 77, tal vez con Antonino Pío, o quizaís con Adriano. Un reciente análisis de la cuestión en Remesal 1996. 
Con referencia a las propiedades de L. Mummitis Niger, Lomas y Sáez ${ }^{70}$ hacen mención de una serie de ánforas olearias con la marca $L . M$. VE. que ellos desarrollan como

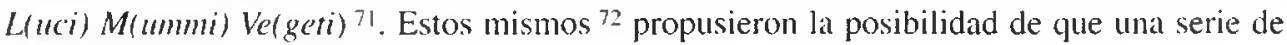
marcas anforarias con las siglas K.V. ya desarrolladas por Manacorda como K(alendarium) $V(\text { egetianum })^{73}$, pudieran datarse antes de mediados del siglo II. La hipotética reconstrucción de Manacorda cuenta ahora con el apoyo de una marca con control de Hispalis y en la que podría desarrollarse muy verosímilmente f(iglina) Veg(etiana ${ }^{7 \dagger}$, que presupone la existencia de un fundus de este nombre en la Bética. Las marcas, mejor col(omi) que c(uratores) ol(earii), de la Bética que aducen Lomas y Sáez no deben datarse en los años 146/161. sino en el siglo III, o por lo menos a finales del siglo II.

Pasemos ahora a otro caso, igual de ilustrador en relación con la tipología y dispersión de propiedades de la aristocracia imperial romana. Es posible que el origen último del cónsul sufecto L. Marius Vegetinus Marcianus Minicianus Myrtillianus y de su hijo L. Marius Vegetinus Lucamus Tiberenus, muerto niño ${ }^{75}$, estuviese en la zona del Ebro ${ }^{76}$. No obstante, y sin desechar la posibilidad de este origen familiar, un trabajo de Genaro Chic ${ }^{77}$ proporciona verosímiles argumentos para vincular directamente al personaje con otra región diferente. Cerca de la antigua Arva (en la provincia de Sevilla, río Guadalquivir arriba de Alcolea del Río), en el lugar llamado "Mejía", se ha documentado la marca de alfar L.M.VE., con nexo entre las dos últimas letras, "V" y "E"; que puede desarrollarse posible, aunque no necesariamente, como Ve(getinus). Además tenemos constancia, por un titulus pictus hallado por Rodríguez Almeida, de la existencia de un f(undus) Veg(etianus?' -etimas?) con control en la zona de Hispalis ${ }^{78}$. Ambos testimonios, aunque no de forma concluyente, pueden muy bien apoyar unos estrechos vínculos, al menos de indole económica, de la familia del consular con la Bética ${ }^{79}$.

Si no hubiese sido por la epigrafía anfórica, concretamente por el desarrollo alcanzado en los últimos años por el estudio de las marcas anforarias, no hubiéramos conocido a la familia de plausible rango senatorial compuesta por L. F(abius?, -lauius?) C(rescens) Sentic(us), L. F(abius?, -lauius?) Lac(?), C. F(abius?, -lauius?) P(?). G. F(abius?, -lanius?) S(entus?, -enticus?), Q. F(abius?, -lauius?) S(entius?, -enticus?) y C. F(abius?, -lauius?) Titianus ${ }^{80}$. Se ha podido identificar esta nueva familia senatorial a través

donde, a partir del estudio de las confiscaciones de Septimio Severo en la Bética y la identificación del Mummins Secundimus de la Vina Sereri 13, el autor realiza un completo estudio del Kalendarium Vegetianum. su composición y propietarios hasta su adscripción al emperador.

70) Lomas \& Sáez 1981.63.

71 Se cita como referencia a Chic. 1977,497 , y Callender. $1965, n^{\circ} 898:$ marcas de comienzos del siglo 11.

72 Lomas \& Sáez 1981, 55-84.

73 Manacorda 1977, 1, 319.

74 Indicación de G. Chic. Véase Rodríguez Almcida 1980, 87. $\mathrm{n}^{\circ} 35$.

75 Cf. Caballos 1990a, 208-210. n 115 y 207-208, n० II 4.

76 Si no en la Lusitania, caso de aceptarse la hipótesis de Bonneville 1982, 5-32. de entender Myrtilianus como expresión de la origo.

77 Chic 1977.334 y 355.

78 Rodríguez Almeida 1980. 87. Podría tal vez (lesarrollarse asimismo cono Veg(etius).

79 No se debe excluir la posibilidad de que la documentación a nuestro alcance también pudiera ser resultado de su actividad como gobernador de la provincia.

80 Cf. Caballos 1990a. 127-128, n 63 A-63 F. 
de una serie de estampillas impresas en ánforas olearias de origen hispano ${ }^{81}$, fabricadas en alfares tanto de la zona de Posadas, en la provincia de Córdoba ("La Dehesilla", "Picachos", "Las Monjas" y "Castillejo") "2, a las orillas del Guadalquivir, como de Écija, en la provincia de Sevilla ("Alcotrista" y "Las Animas") ${ }^{83}$, en la ribera del Genil.

La mayoría de las estampillas repiten las siglas " $C V$ ". Habitualmente se venía leyendo, en unión de la "F" que en ocasiones le sigue, como una abreviatura de "CVF(iense)" 84 . Sin embargo esta posibilidad debe excluirse al aparecer en otras ocasiones tras " $C V$ " no una " $F$ ", sino una " $E$ " 85 . No corresponderían tampoco estas siglas al nombre de la propiedad, puesto que aparecen en figlinas muy alejadas entre sí. Chic cree que podría desarrollarse como $C$ (larissimus) $V(\text { ir })^{86}$ al estudiar marcas norteafricanas donde en algunas ocasiones aparece el calificativo clarissimus uir, unas veces desarrollado y otras sin desarrollar, acompañando a un mismo nombre ${ }^{87}$.

Nos cncontraríamos así con una nueva familia con al menos seis miembros, de reciente inclusión en el ordo senatorius a fines del siglo II. Desgraciadamente no conocemos el posible desarrollo de la abreviatura del nomen. aunque es mucho más razonable suponer $F$ (abius) ${ }^{\text {s. }}$, que F(lauius) ${ }^{89}$, por la mayor frecuencia de este gentilicio entre las familias privilegiadas de la Bética ${ }^{90}$.

Por la ubicación de sus propiedades hay que suponer un origen bético para estos personajes. Entre estas propiedades deben contarse tjerras de la zona de Posadas, para cuyas producciones dispusieron de la alfarería de "La Dehesilla". cronológicamente operativa, de forma aproximada, bastante probablemente entre los años 140 y 198 p.C. "I, la de "Picachos", cuyo nombre romano pudo ser F(iglina) M(aior) o F(iglina) M(ediana)"2. que llegaría a producir únicamente para esta poderosa familia, y la de "Las Monjas", que pudo haber sido denominada F(iglina) $P(r i m a){ }^{93}$. En la zona del Genil poseerían otras

RI Callender, 1965.851. La difisión de estas marcals es amplísima. cf. Chic 1985. 21.

82 Chic 1985, 18-23. Según este autor. la actividad del taller alfirero de "La Dehesilla" comenzaría hacia la segunda mitad del siglo I p.C. datíndose posiblemente su final en época de Severo Alcjandro. A lo largo de este dilatado períno su actividad se fue haciendo cada vě más compleja hasta quedar bajo el control de la familia de L.F. Crescens en el último cuarto del siglo II p.C. "Picachos" es más moderna, no comenzando a trabajar antes de la segrunda mitad del siglo It p.C. Para Chic debió tratarse de una extensión del anterior taller: "Las Monjas" seria una alfarería de época post-severiana. según Rodriguez Almeida.

8.3 Chic 1985, 36-38. "Alcotrista" es un gran alfar con una producción muy heterogénea, no limitíndose a las ánforas, remontando sul cronología al siglo I. para llegar al menos hasta fines del siglo II p.C. Las marcas $L F C$. LFCS. LFCCOLL y similares son datadas por C. Panella en la segunda mitad del siglo Il p.C. (cf. Panella 1983, 240). Auncue Chic no lo indica, la marca M.F.S. que procede de este alfar podría corresponder también a otro mienbro. el séptimo, de la familia senatorial de que ratamos. "Las Ánimas" fabrica desde mediados del siglo I p.C. y a mediados del siglo it formaria parte de las propiedades de la misma familia senatorial.

nt En relación con el BARCVFIENSE del titulus pictus CIL. XV. 2.3977 del 149 p.C

s. La marca LFCCVEXFP procedente posiblemente de "Las Monjas" y encontradia en el Testaccio.

s6 Chic. 1985. 21. Se apoya en la hipótesis de Manacorda 1983. 483-500.

87 Esta hipótesis fue asumida por Jaceques 1990a, 865-899.

88 Así Jiccules, ibid.

s9 Chic, 1985, 145.

\%) Castillo 1975. 6+1-642.

91 Cuando aparecen en esta figlina las marcas $L F C F M$ y CFS. Callender p. 155. $n^{\circ} 851$. Chic se interroga sobre si en épocal de Severo Alejandro. a la que corresponden las marcas F.CVCVM. la propiediad habria pasado o no a manos del Estiado.

9. Chic 1985.20-22.

p. Il.. 1985. 22-23. 
propiedades. para las que trabajaban las figlinas de "Alcotrista", cuya designación antigua podría haber sido el desarrollo de la abreviatura $C O L(\ldots)$, y "Las Animas", la romana F(iglina) CATL(...).

Ahora otro caso similar. Al igual que sucedía con la probable familia senatorial de los $F$ (abii? -lauii?) $\% 4$, encontramos marcas de ánforas con las siglas $P M O$ a las que acompañan las siglas $C V$, que muy bien pueden desarrollarse asimismo como c(larissimus) u(ir). Estas marcas ${ }^{95}$, con una cronología de Eliogábalo - Severo Alejandro. proceden de la alfarería de "La Corregidora", la posible $F I G(l i n a)$ EDOP(piana?), en la orilla izqujerda del Guadalquivir en el área de Posadas. Otro taller no identificado, que marcó sus ántoras con la estampilla $P$ MOCVI/F PALMA, también habría trabajado para esta propiedad. Desgraciadamente, y aquí una de las mayores dificultades de la epigrafía anfórica. la abundancia de gentilicios que comienzan por " $\mathrm{M}$ " imposibilita la restitución. con algún grado de certidumbre, de los tria nomina, que deben quedar como $P(--) M(--) O(---), y$, por tanto, del gentilicio de esta familia de presumible origen bético $\%$.

De la antigua figlina Scalensia, situada en el "Cerro de los Pesebres" (Peñaflor, Sevilla) ${ }^{97}$, proceden las marcas $L F C C V F S C A L$ y variantes. J. Remesal 98 lee L(ucius) $F$ (abius) C(ilo) c(larissimus) u(ir), seguido del nombre del taller anforario, $f($ iglina) Scallensia), asignando por tanto explotaciones en la región al poderosísimo L. Fabius Cilo Septiminus Catinius Aciliamus Lepidus Fulcinianus, cónsul en el 193 y nuevamente en el $204^{99}$. Remesal remarca asimismo el papel del personaje como suministrador de aceite bético al ejército de la Germania. Otras estampillas de este taller corresponderían, según Remesal, a $L$. F(abius) F(ortunatus), hijo de $C i l o{ }^{100 ;}$ mientras que asigna la marca LFLVCCVFS, de la misma procedencia, al c(larissimus) u(ir) L(ucius) F(abius) Luc(ilianus), hijo del anterior ${ }^{10 !}$.

Pero, quien efectúa el análisis más exhaustivo y actualizado de las marcas L.F.C., sus variantes y todas aquéllas que con éstas pudieron estar relacionadas es G. Chic García ${ }^{102 .}$ Éste enumera todas las improntas anforarias conocidas hasta el momento de esta familia de sellos, agrupadas en los respectivos centros productores de procedencia, un total de veinticinco a lo largo del Valle del Guadalquivir. Cronológicamente el recorrido abarca desde época julio-claudia, hasta el final de época severiana. Este completísimo catálogo (recogido asimisno en forma de cuadro recapitulativo al final), así como las conclusiones que se adjuntan, son hasta ahora el máximo exponente de las amplias posibilidades de este campo de indagación histórica, pero a la par, no sólo es muestra de las dificultades,

94 Vide supra p. 82.

95 Callender 1965. 1352.

96 Los gentilicios de senadores de origen hispano que comienzan por la letra "M" son : Maecius, Maenius, Manilius, Marcius, Marius, Memmius, Messius, Minicius y Mummins (ct. los índices onomásticos de nuestra obra Caballos 1990a).

97 Es el antiguamente llamado "Cortijo bajo del Serno", nombre con el que lo recoge Ponsich 1979.139. $n^{\circ}$ 152), y también conocido como "Cortijo del Molino" (Chic 1985, 26).

y8 Remesal 1989b. 119-153. En contra de la interpretaciones de Remesal 1989b. Jacques 1990. y Chic 1994. se manifiesta J. H. Van der Werff 1995.

99 Caballos 1990a. 132-135, nº 66.

100 O nieto. Cf. Caballos $1990 \mathrm{a}, 137,11^{\circ} 68$.

16) Cf. Caballos 1990a. 128-129. n 64.

102 Ct. Chic 1994. 171-233. 
limitaciones, inseguridades y errores de apreciación en la identificación de los personajes cuyas siglas transmite la documentación disponible, sino que nos previene de la asimilación simplista entre productores, envasadores y distribuidores de aceite.

Hasta aquí los casos que recogemos para evidenciar la significación de la explotación y comercialización a gran escala del olivar bético. Un solo detalle para concluir. En época de los Flavios, la de mayor dinamismo y despegue en la producción aceitera, las marcas que más abundan son las de los Valerii. ¿Dónde están representados en los más elevados ordines? A la par, según las conclusiones de Chic, hasta el momento carecemos de argumentación que. a partir de tituli picti. certifique la actuación directa de ningún senatorial como diffusor olearius. Esta doble nota quizás pueda servir para evitar toda tentación mecanicista en la fundannenlación económica de la promoción.

Los principios, esto es, el programa ideológico del régimen imperial romano. de forma diferente a cómo actuaban en relación con los equites, incorporaban algunas limitaciones en lo que se refiere a la actividad económica y a la implantación local de los bienes de los senadores. Si bien la lex Claudia de naue senatorum quedaba ya tan lejos como el 218 a.C., y en la práctica ya se había acabado encontrando fórmulas para suavizar sus repercusiones 113.3, por imperativo legal los senadores aún seguían estando excluidos del desempeño de funciones locales, además de verse obligados, tanto a la inversión de un significativo porcentaje de sus bienes en tierras en Italia, como a domiciliarse en la Urbe.

Si los senadores no desempeñaban magistraturas municipales, y por lo tanto estaban excluidos de las aportaciones de las correspondientes summac homorarice, ello de ninguna manera les impediría contribuir a la magnificencia urbana de las provincias, no sólo por vía de las actitudes evergéticas, sino por la fórmula del patronato.

Según Plinio, Trajano impuso a los candidatos a las magistraturas senatoriales la obligación de invertir un tercio de la fortuna familiar en bienes raíces en Italia. El mismo Plinio aduce las motivaciones y el alcance de esta medida, que por lo pronto supuso un encarecimiento del suelo en Italia y el correspondiente abaratamiento de las tierras provinciales ${ }^{10-4}$. Un segundo reglamento, cronológicamente no muy distante. debido esta vez a Marco Aurelio, supuso una suavización del alcance porcentual sobre los bienes de los senadores. Ahora no sería un tercio, sino que se bajaba hasta un cuarto el monto patrimonial afectado por la medida 105.

A pesar de sa importancia. no debe sin embargo exagerarse el alcance de las anteriores medidas, bien, al menos, por la vía de la dificultad de un seguimiento exhaustivo de su cumplimiento, bien por lo poco dilatado del período de aplicación y vigencia. Con el tiempo las repercusiones se minimizarían, por lo que no habría que obsesionarse en buscar por esta vía el argumento de base de una disolución de los vínculos de los laticlaves con las

10.3 Livio 21.63. Cf. Pavis d'Escurac 1977. 339-355 y D'Arms 1981.

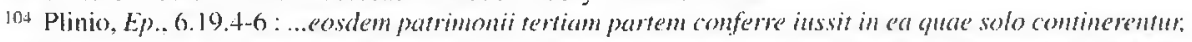

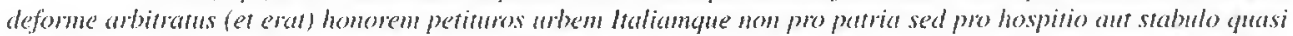

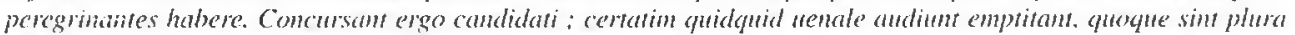

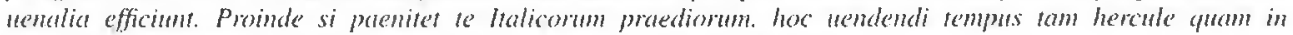
proninciis comparandi, dum idem candidati illic uendunt ut hic entant. Vale.

105 SHA, Vita Marci. 11.8: Tra<iasnique praecepta uerecunde consuluit. leges esiam addidit de

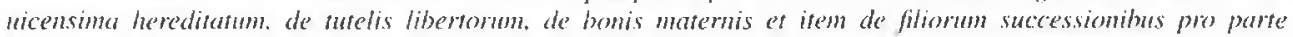
materna. atqula le senatores peregrini quartam partem in halia possiderent... 
comunidades provinciales de origen. El caso de los Messii Rustici es paradigmático al respecto para época adrianea y post-adrianea. mostrándonos la espectacular extensión de los bicnes de esta familia en la provincia, en un proceso de progresiva concentración de la propiedad bien documentado como tendencia en éste y otros casos, especialmente a partir de épocal severiana. Por haber tratado por extenso de este tema con antelación, no creemos pertinente en este caso repetirnos 100 .

Como contrapartida, también por la funcionalidad de los clarissimi como magistrados de la administración imperial, se establecieron naturalmente nuevos vínculos personales, ambientales y económicos, con Roma, Italia y, en menor medida, con las provincias. Con Roma. primero por la obligación por imperativo legal de ubicar en ésta el domicilio oficial, pero también por la proximidad al poder, por el prestigio derivado de la residencia en la Urbe y, asimismo, evidentemente por funcionalidad y operatividad como magistrados y miembros de la Asamblea que eran. Fundamentalmente son la documentación literaria, así como los datos que se desprenden del estudio de las fistulae aquariae y de la epigrafía latericia, los que se encargan de evidenciarnos la ubicación y presumible prestancia de las villas urbanas de algunos de estos grandes próceres de extracción bética. Los Cornelii Pusiones ${ }^{107}$ y los Valerii Vegeti ${ }^{108}$ plantaron sus lares en el Quirinal, las residencias de los Annii Veri ${ }^{109}$ se ubicaban iatata aedes Laterani y en el monte Celio, las de L. Fabius Cilo: 10 en el Aventino y la Via Ostiense, y la de los Platorii Nepotes $11 \mathrm{l}$ en el ámbito de la actual "Via dei Fori Imperiali".

Tenemos asimismo bien documentadas propiedades de los senadores de la Bética fuera de Hispania. Ya hemos tratado con antelación el caso de P. Acilius Attianus, puesto que muchas de las propicdades que de él conocemos debieron haber llegado a sus manos aún como caballero, con antelación a su ingreso en el amplissimus ordo. M. Aponius Saturninus, el uir praetorius mencionado por Suetonio 112 podría identificarse con el personaje homónimo, rico propietario de tierras, mencionado en papiros egipcios de época tiberiana ${ }^{13}$.

De las amplísimas propiedades de los Mummii Nigri en Viterbo tenemos plena constancia documental. Concretamente conocemos la uilla Caluisiana, quae est ad aquas Passerianas (en las proximidades de la wia Cassia), propiedad de L. Mummius Niger. Este personaje construyó un acueducto para llevar agua a la finca. Para ello su influencia le permitió obtener permiso de paso por terrenos públicos, mientras que, complementariamente, compró a los particulares los terrenos privados por los que discurría la conducción 114. Aún dentro de esta familia, del hecho de la existencia de una inscripción referente a L. Mummius Niger Q. Valerius Vegetus Setrerinus Caucidius Termullus, hijo del

noo Gunzález \& Caballos 1983, 157-171. Sobre los micmbros de la familia ct. Caballos 1990a, n 59-60, 120-26.

107 Cf. Caballos 1990a. $n^{\circ}$ 54-55.

$108 \mathrm{Cf}$. Id. $1990 \mathrm{a}, \mathrm{n}^{\circ} 165-166$.

109 Cf. $J d .1990$ a. $n^{\circ} 23,25-26,29-33$.

110 Cf. Id. $1990 \mathrm{a}, \mathrm{n}^{\circ} 132$.

111 Cf. Id. 1990a. n 249 y 252

112 Calig.. 38,4 : cf. Caballos 1990at. $n^{\circ} 36$.

113 P. Osl. $2,33=$ Klio 22, 1929.221 s. (del año 29) : Wilcken, Symb. Osl. vil, 1928, p.33 (a.31) : P. Ryl., II, 131. 14 s. (a. 34) y P. Ryl, 135, 9.

114 Entre estos antiguos propietarios es digno de mención un $P$. Thallitus Varro, en el que se ha querido ver al cónsul del año 127. CLL. XI. $3003=1 L S$, 5771. Ct. Caballos 1990a, 17 $129 \mathrm{~A}$. 
anterior, en la Apulia, con una dedicación a Iuppiter Dolichenus Exuperantissimus ${ }^{115}$, podría inferirse tal vez que poseyera bienes en aquella región, pues no nos explicamos de otra manera las relaciones con Aecae.

Un caso peculiar, al que ya antes nos referimos al tratar del caballero $L$. Baebius Balbus, es el de la concentración de villas en Tibur, refugio de Adriano. Éste debe ser analizado, más como argumento de carácter político. que como un dato meramente económico. Su explicación está en el interés - o la necesidad - por exteriorizar fidelidad a Adriano tras la trascendental decisión tomada por éste de romper amarras con la política trajanea. manifestada en la ruptura con los supervivientes del círculo de su antecesor, que se hizo evidente con la defenestración de P. Acilio Attiano. Una etapa se había cerrado, y se abría otra nueva en la historia de Rona. Muchos de los miembros de su círculo. ahora remozado - entre los que hay que citar por su especial protagonismo y relevancia presente y futura a los Annii Veri o a los Messii Rustici-, siguieron teniendo extracción bética. ¿,Por qué no?, si aún había cantera y gentes que seguían reuniendo requisitos idóneos para la promoción, en este caso no sólo económica. ni social, escalones para muchos ya alcanzados, sino fundamentalmente política. Entre los personajes de rango senatorial para los que tenemos documentada la presencia en Tibur hay que mencionar a M. Accema Saturminus ${ }^{116}$, L. Comelius Pusio ${ }^{17}$, los Manilii ${ }^{118}$, y los ya reiteradamente citados Messii ${ }^{119}$.

Para concluir, expresamos ahora algunas reflexiones de carácter general, a modo de complemento de lo que hemos ido describiendo a lo largo de las páginas precedentes. Una primera evidencia resulta: a lo sumo habitualmente podemos Ilegar a conocer sólo un cierto porcentaje de la exteriorización de la riqueza de las elites de la Bética. Podemos identificar a éstos como "ricos", sin que en la mayoría de los casos podamos averiguar los procedimientos últimos, las fórmulas y la dinámica precisa, concreta y cotidiana por los que llegaron a serlo. Conocemos la tipología de su riqueza. podemos incluso hasta elucubrar o intuir su alcance, pero no podemos realizar una precisa cuantificación de ésta. ni conocer con precisión y exhaustividad sus repercusiones últimas - por ejemplo en las relaciones horizontales entre familias de la aristocracia, o verticales, generando lazos de dependencia y el tren de vida concreto que posibilitaba. así como tampoco precisar las diferencias reales entre unos y otros miembros del mismo ordo: ni siquiera en el caso de los senadores, por lo tanto mucho menos en el más heterogéneo orden ecuestre. También sería de gran interés conocer los casos, y si tuera posible una cuantificación porcentual y los ritmos de los procesos de pérdida patrimonial, hasta incluso. en su caso, el desenlace del desclasamiento. Es evidente, sin embargo, que por imagen corporativa y por interés informativo. salvo circunstancias excepcionales por tratarse de casos extraordinariamente llamativos, las fuentes habitualmente no dejan rastros de estos procesos. Sólo nos llegan los vacíos informativos. las soluciones de continuidad en las trayectorias familiares.

Por consiguiente, para conocer con carácter general muchas de las cuestiones que acabamos de enunciar. debemos acudir. no solamente a lo que sabemos en concreto de la

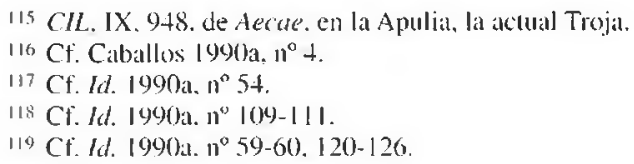


riqueza de los caballeros y senadores béticos, sino que resulta válida la extrapolación de las características económicas genéricas de los incluidos en los ordines, que, sobre todo en el caso de los senadores, siguen unas pautas similares, con los normales márgenes de diferenciación cuantitativa ${ }^{120}$.

Pero. sobre todo, de nuevo en la línea de prevención ante fáciles pero erróneos mecanicismos, y para evidenciar lo mucho que se nos escapa. mostrando hasta qué punto incorporan arcana los procesos de promoción, y especialmente los argumentos económicos implícitos, vamos a acudir a un socorrido texto de Tácito. En este relato se relativiza el papel de los criterios económicos, manifestándose la significación de los argumentos de carácter político en la promoción, con consecuencias económicas a posteriori. Es ésta la única ocasión, si no al menos la más clara, y aún así indirectamente. en que contamos con un presunto testimonio sobre la opinión que el beneficiario expresa acerca de la propia promoción a los ordines. Se trata del discurso que Tácito puso en boca de Séneca, cuando éste vio peligrar su situación a la muerte de Burro y decidió solicitar del emperador el retiro. Si bien es necesario contar con todo lo que en el historiador hay de licencia retórica y, por tanto restringir el alcance del testimonio, sí que resulta suficientemente elocuente de la opinión del círculo de Tácito. que tenía información suficiente para saber y decir lo que decía, acerca de este tipo de rápido ascenso y de las vías que lo posibilitaron. Tácito nos describe, con una cualificación moral neutra, las circunstancias extraordinarias de un enriquecimiento exponencial por beneficio del príncipe. El libre juego de la política actuando aquí, en lo concreto, con prelación a los argumentos de estricta y aséptica dinámica económica : At Seneca criminantium non ignarus, prodentibus iis quibus aliqua honesti cura et familiaritatem eias magis aspernante Caesare, tempus sermoni orat et accepto ita incipit : 'quartus decimus ammus est, Caesar, ex quo spei tuae admotus sum, octauus ut imperium obtines : medio temporis tantum honorum atque opum in me cumulasti ut nihil felicitati meae desit nisi moderatio eius. utar magnis exemplis nec meae fortunae sed mae. abaus tuus Augustus Marco Agrippae Mytilenense secretum, C. Maecenati urbe in ipsa uelut peregrinum otium permisit; quorum alter bellorum socius, alter Romae pluribus laboribus iactatus ampla quidem sed pro ingentibus meritis praemia acceperant. ego quid aliud munificentiae tuae adhibere potui quam studia, ut sic dixerim, in umbra edacata, et quibus claritudo uenit, quod iutuntae tuae rudimentis adfuisse wideor, grande huius rei pretium. at tu gratiam immensam, inmumeram pecuniam circumdedisti adeo ut plesumque intra me ipse woluam : egone equestri et prouinciali loco ortus proceribus ciuitatis adnumeror? inter nobilis et longa decora praeferentis nouitas mea enituit? ubi est animus ille modicis contentus? talis hortos extruit et per haec suburbana incedit et tantis agrorum spatis, tam lato faenore exuberat? una defensio occurrit cuod muneribus tuis obniti non debui ${ }^{121}$.

120 Una síntesis introductoria sohre la riqueza y obligaciones económicas generales, o aquéllas de cualquier otra índole pero con repercusiones sobre sus patrimonios, de tos miembros del orden senatorial en Tatbert 1984, 47-76. Para las mismas cuestiones releridas a los equites puede consultarse Demougin 1988. 73-134.

121 Tácito. Ann.. 14.53.1-23. 